\title{
Why We Persist: An Intersectional Study to Characterize and Examine the Experiences of Women Tenure-Track Faculty in Engineering
}

\section{Dr. Monica Farmer Cox, Ohio State University}

Monica F. Cox, Ph.D., is Professor and Chair in newly created Department of Engineering Education at The Ohio State University. Prior to this appointment, she was a Associate Professor in the School of Engineering Education at Purdue University, the Inaugural Director of the College of Engineering's Leadership Minor, and the Director of the International Institute of Engineering Education Assessment (i2e2a). In 2013, she became founder and owner of STEMinent LLC, a company focused on STEM education assessment and professional development for stakeholders in K-12 education, higher education, and Corporate America. Her research is focused upon the use of mixed methodologies to explore significant research questions in undergraduate, graduate, and professional engineering education, to integrate concepts from higher education and learning science into engineering education, and to develop and disseminate reliable and valid assessment tools for use across the engineering education continuum.

\section{Dr. Joyce B. Main, Purdue University, West Lafayette (College of Engineering)}

Joyce B. Main is Assistant Professor of Engineering Education at Purdue University. She holds a Ph.D. in Learning, Teaching, and Social Policy from Cornell University, and an Ed.M. in Administration, Planning, and Social Policy from the Harvard Graduate School of Education.

\section{Dr. Ebony Omotola McGee, Vanderbilt University}

Ebony O. McGee is an Assistant Professor of Diversity and Urban Schooling at Vanderbilt University's Peabody College and a member of Scientific Careers Research and Development Group at Northwestern University. She received her Ph.D. in Mathematics Education from the University of Illinois at Chicago; and she was a National Academy of Education/Spencer Foundation Postdoctoral Fellow and a National Science Foundation Postdoctoral Fellow. As a former electrical engineer, she is concerned with science, technology, engineering, and mathematics (STEM) learning and participation among historically marginalized students of color. Her research focuses on the role of racialized experiences and biases in STEM educational and career attainment, problematizing traditional notions of academic achievement and what is mean to be successful yet marginalized, and STEM identity and identity development in high-achieving students of color. She is currently the PI on two studies funded by NSF, the first of which investigates the causes behind why African Americans remain one of the most underrepresented racial groups in engineering faculty positions. The second study is working toward the design of a holistic racial and gender attentive mentoring program for engineering $\mathrm{PhD}$ students of color.

Matilde Luz Sanchez-Pena, Purdue University, West Lafayette (College of Engineering)

Matilde Sanchez-Pena is a first year PhD student in the Engineering Education program at Purdue University. Her research interests are diversity in engineering, education policy making and the effective teaching of statistics in engineering.

Dr. Nikitha Sambamurthy, Purdue University, West Lafayette (College of Engineering) Jung Sook Kim, Ohio State University

Ph.D. in Department of Teaching \& Learning, College of Education \& Human Ecology, at the Ohio State University 


\section{Why We Persist: An Intersectional Study to Characterize and Examine the Experiences of Women Tenure-Track Faculty in Engineering}

This project applies an intersectionality framework to identify why tenure-track women of color (WOC) persist as engineering faculty. Project goals will be achieved through the compilation and analysis of longitudinal data of WOC faculty in engineering using an American Society for Engineering Education (ASEE) faculty database; the development of a national survey investigating the perspectives of all women engineering faculty at U.S. engineering institutions on issues of race, class, and gender; and the exploration of similarities and differences in horizontal and vertical intersectionality across WOC groups via the collection and analyses of narratives of approximately 65 engineering WOC tenure-track faculty.

Our overarching research question explores the following: How do women engineering faculty's representation and experiences differ in academic engineering as a function of racelethnicity, class, and faculty rank? Informed from Patricia Hill Collins' framework of intersectionality, ${ }^{1}$ this research applies a mixed methods approach across three interrelated and parallel research phases. The specific research questions related to each phase, their preliminary findings, and future work are described in the following sections.

\section{Phase A: Institutional Analyses with Existing Databases}

In this stage, existing databases are used to answer the following research questions:

- Which institutional-level factors influence the proportion of WOC faculty in engineering?

- Are there differences when engineering female faculty are disaggregated by race/ethnicity (i.e., Asian, Latina, and African-American)?

The available databases used for this purpose are (1) institutional level data collected yearly by ASEE on the aggregated number of engineering faculty by gender and ethnicity, (2) institutional characteristics gathered by the Integrated Postsecondary Education Data System (IPEDS), and (3) public information about the list of NSF-funded ADVANCE grantee institutions. Faculty data were available via an ASEE data mining tool for the years 2001 to $2015,{ }^{2}$ which allows for an assessment of the growth in the number of WOC through this 15-year period; IPEDS data permits analyzing such trends considering different groups of institutions based on their characteristics; and knowing which institutions have implemented ADVANCE initiatives, help assessing their advancements in faculty diversification. These data of 354 institutions were available for this part of the study, limiting the generalizability of our descriptive and inferential analyses.

Preliminary findings of this phase include a descriptive analysis of the available data and regression models of two time points. Descriptive analyses showed a general increase in the number of WOC across all institutions in the database. While in 2001 there was a total number of 349 WOC engineering faculty across all institutions, representing only $1.8 \%$ of all faculty, in 2015 there were a total of 1,552, representing 5.4\% of all faculty. However, 70\% of the institutions with no WoC in 2001 still did not employ WoC faculty in 2015. In addition, the concentration of WOC differs across institution types. Predominately White Institutions (PWIs), in general, report lower proportions of WOC than non-PWI's (e.g., minority-serving institutions). Asian American female faculty constituted the biggest proportion of WOC among all different groups of institutions. African Americans constituted 45\% of the female engineering faculty at Historically Black Colleges and Universities (HBCUs) compared to about $3 \%$ of the 
female engineering faculty at PWIs. However, when compared to the total engineering faculty African American female faculty represent only $6.7 \%$ and $0.4 \%$ in each of these groups of institutions, respectively. Latina faculty were outnumbered by Asian American female faculty at Hispanic-serving institutions (HSIs).

Ordinary least squares regression models using only data at two time points (2003 and 2015) were used to explore the effects of a variety of institutional variables at 2003 in the proportion of WOC engineering faculty at 2015. It was hypothesized that institutions with female leaders, an explicit commitment to diversity (expressed through ADVANCE initiatives), and those with a diverse student body would have higher proportions of WOC engineering faculty. Other institutional variables were considered for controlling purposes such as their Carnegie classification, private/public control source, minority-serving institution designation, institution size, urban status, and institutional selectivity. Individual models were created to study the proportions of (a) all women, (b) all WoC, (c) African American female faculty, (d) Asian and Asian American female faculty, and (e) Latina faculty.

The gender of the leadership had a positive effect on the prevalence of African American engineering faculty. However, there is no effect on the proportion of other WoC faculty or WoC in the aggregate. The presence of ADVANCE programs did not have an effect on the proportions of WoC when controlling for other institutional variables. Also, ethnic diversity (but not gender diversity) in 2003 is positively correlated with the proportion of total WoC and for African American female faculty in 2015.

Ongoing and future quantitative analyses using the described data include, (1) clustering analysis of the type of institutions that have the higher/lower numbers and proportion of WOC engineering faculty; (2) a Granger analysis ${ }^{3}$ that would correlate the considered variables across different points in time; (3) a longitudinal analysis that would allow extracting the effect of each variable across time; and (4) a survival analysis of the event when institutions started hiring WOC engineering faculty.

\section{Phase B: Development of a National Survey of Women Engineering Faculty}

Although our quantitative analysis studies institutional level variables, it cannot capture how the WOC faculty experience such institutional elements. In addition, the sample of institutions considered in the quantitative analysis is limited. In order to explore the actual experiences of women faculty, capture the differences across race and class, and expand the generalizability of such exploration, we are developing a National Survey of Women Engineering Faculty that aims to answer the following research questions:

- How do women faculty in engineering self-identify race, class, and gender?

- How do individual, institutional, and symbolic dimensions of oppression ${ }^{1}$ connect to one's persistence as a woman faculty in engineering?

- In what ways, if any, do persistence align with intersectionality?

In this stage, two parallel objectives are being advanced: (1) the creation of a National Database of Engineering Faculty and Institutional Leaders, and (2) the development of a scale to study their experiences through the lens of intersectionality. Each of these steps is further described next.

\section{Creation of a National Database of Engineering Faculty and Institutional Leaders}

A total of 619 institutions with 3,245 ABET-accredited engineering programs were identified based on ABET's website in January 2016. On Spring 2016 our data collection process 
started, to gather information of professors' name, title, picture, and contact information at each of the identified programs is being collected. In addition, information on the institutions' president, provost, and diversity officers is also being collected. All the information is being accessed through publicly available sources online using a web-crawler. As of November, of 2016, there was a $40 \%$ advancement on the data collection process to complete the database. Once the survey is launched, the gathered data will help us conduct analyses similar to those described in Phase A to support stronger conclusions on the institutional elements influencing the advancement of WOC engineering faculty.

\section{Scale Development}

For the scale development, the team generated an initial pool of items exploring how intersectionality relates to women engineering faculty's persistence from individual, symbolic, and institutional perspectives. The survey is being generated through a step-by-step process of planning, construction, qualitative evaluation, and validation. ${ }^{4}$ In the planning phase, we specified our target group as tenured/tenure-track women faculty in engineering, and a statement of the purpose of the intended survey was formulated accordingly. Construction of the survey occurred after conducting an extensive literature review on the persistence of women faculty and the operational definitions of persistence as the constructs were made and the components to be measured were identified. Grounded in the theory of intersectionality of race, class, and gender, a pool of Likert scale question items was written and reviewed by the item writers. Through the methodological consultations with a research center at the project's lead institution as well as the four Advisory Board members with expertise in higher education, diversity, and gender studies, the initial scale/survey questionnaire was discussed and assessed for its qualitative validation. After multiple revisions and/ or deletions, approximately 72 survey items were ready for a pilot testing. Ongoing content validation and pilot testing will be conducted to confirm the validity and reliability of the instrument and its alignment with intersectionality and persistence prior to launching the national survey.

\section{Phase C: Interviews with Women of Color Engineering Faculty}

Our research will use interviews to examine the experiences of women of color in tenuretrack faculty positions in engineering. We especially want to interview the WOC in a focus group format (about 5 faculty per group discussion) to learn about the factors that influenced your career decision-making as well as your persistence in academia.

Through the institutional analysis above, we identified colleges and universities with one or two WOC faculty in engineering to recruit potential participants for the next phase of our project, interviews. We are seeking assistance from the Deans of the universities with identifying engineering or computing women of color faculty. If they are willing to assist, they submit their contact information and we will send each potential participant a formal letter of invitation. The focus group interviews will coincide with the annual conference American Society for Engineering Education in Columbus, $\mathrm{OH}$ for the 124th Annual Conference \& Exposition, June $24-28,2017$.

\section{Acknowledgment}

This material is based in part upon work supported by the National Science Foundation under Grant Numbers 1535456 and 1712618. Any opinions, findings, and conclusions or 
recommendations expressed in this material are those of the author(s) and do not necessarily reflect the views of the National Science Foundation.

\section{References}

1. Hill Collins, P. Toward a new vision: Race, class, and gender as categories of analysis and connection. Race Sex Cl. 1, 25-45 (1993).

2. American Society for Engineering Education. Engineering Database System. Retrieved from http://edms.asee.org/session/new, March 19, 2017.

3. Granger, C. W. J. Investigating causal relations by econometric models and cross-spectral methods. Econometrica. 37 (3): 424-438 (1969).

4. Benson, J. \& Clark, F. A guide for instrument development and validation. Am. J. Occup. Ther. 36, 789-800 (1982). 